BRANDÃO AA; COSTA CA; GALIZONI FM; CAVALCANTE TFM; NEVES AC. 2015. Perfil socioeconômico dos consumidores de hortaliças em feiras livres na microrregião de Januária. Horticultura Brasileira 33: 119-124. DOI - http://dx.doi.org/10.1590/S0102-053620150000100019

\title{
Perfil socioeconômico dos consumidores de hortaliças em feiras livres na microrregião de Januária
}

\author{
Antônio A Brandão; Cândido A Costa; Flávia M Galizoni; Thâmara FM Cavalcante; Ágatha C Neves \\ UFMG-ICA, Av. Universitária 1.000, Bairro Universitário, 39404-547 Montes Claros-MG; toniagrick@yahoo.com.br; candido-costa@, \\ ufmg.br; flaviagalizoni@yahoo.com.br; thamara_fmc@yahoo.com.br; agathanescobar@yahoo.com.br
}

\section{RESUMO}

Os consumidores cada vez mais estão buscando uma alimentação saudável e diversificada, elevando a procura por hortaliças. As hortaliças são encontradas em vários segmentos de mercado, como sacolões, supermercados e também nas feiras livres. Poucas informações existem a respeito da importância das feiras no cotidiano do consumidor que compra hortaliças na região do norte de Minas Gerais. Diante disso o objetivo deste trabalho foi analisar características socioeconômicas de consumidores de hortaliças em feiras livres, nas cidades de Chapada Gaúcha, Itacarambi, Januária e Manga na microrregião de Januária, norte de Minas Gerais. Foram aplicados ao todo 107 questionários nos municípios, de acordo com o volume de pessoas que frequentaram cada feira na respectiva ocasião. Observa-se que a maior parte dos consumidores são mulheres, não aposentados e com idade inferior a 54 anos sendo que em Chapada Gaúcha essa frequência chega a $100 \%$. As pessoas vão à feira semanalmente e a maioria relatou comprar hortaliças somente nas feiras por valorizarem qualidade e tradição; o preço como critério de escolha apresentou pouca influência. A maioria dos consumidores em Itacarambi e Januária, afirmaram gastar mais de R \$ 30,00 por ida à feira e em Manga e Chapada Gaúcha gastam entre R\$10,00 e R\$ 20,00 . As mulheres foram responsáveis pela compra de hortaliças nas feiras estudadas. A oferta de produtos sem uso de agrotóxicos e fertilizantes químicos gera confiança e fidelização dos consumidores. Há direcionamento na preferência pela compra de algumas espécies na feira livre. Espécies como brócolis e couve-flor foram lembradas por parte dos entrevistados e não são encontradas nas feiras da região com freqüência, indicando oportunidades de diversificação da produção.

Palavras-chave: olerícolas, mercado, renda.

\section{ABSTRACT}

Socioeconomic profile of vegetable consumers in street markets in the microregion of Januária, Brazil

The increasing search for healthy habits implies an increasing demand for vegetables. Vegetables are found in many market segments such as retail shops, supermarkets and street markets. Little information exists about the importance of street markets in the daily life of people and their buying habits in the northern region of Minas Gerais state. The objective of this study was to analyze the socioeconomic characteristics of vegetable consumers at street markets in Chapada Gaucha, Itacarambi, Januaria and Manga counties, in the microregion Januaria, located on the north of Minas Gerais state, Brazil. A hundred and seven questionnaires were administred according to the volume of people attending each fair at the moment. A majority of women consumers, not retired and younger than 54 years old, this data being observed at Chapada Gaucha with a frequency of $100 \%$. People stated to go to the street markets every week to buy vegetables due to product quality and tradition, not using price as a criterion of choice. Most of consumers in Itacarambi and Januaria reported spending more than US\$17.00 on the street markets, whereas in Manga and Chapada Gaucha they spent between US\$6.00 and US\$11.00. The women proved to be the major buyers at the street markets studied. The product offered without pesticides and chemical fertilizers creates trust and loyalty of consumers. A preference for purchasing certain species at the street markets was noticed. Species such as broccoli and cauliflower were mentioned by the interviewers not to be found frequently at street markets in the region, indicating opportunities to diversify production.

Keywords: vegetables, market, income.

\section{(Recebido para publicação em 1 de julho de 2013; aceito em 18 de setembro de 2014) (Received on July 1, 2013; accepted on September 18, 2014)}

\begin{abstract}
$\mathrm{A}$ preocupação em ingerir alimentos com bom padrão nutricional e o mais natural possível caracteriza cada vez mais a mudança de costume alimentar das pessoas. A relação entre alimentação e saúde influi diretamente nas mudanças de hábitos de grande parte da população, que cada vez mais busca alimentos saudáveis e diversificados, elevando a procura por frutas e hortali-
\end{abstract}

ças (Cerdeño, 2006).

As hortaliças são encontradas em vários segmentos de mercado, como sacolões, supermercados e nas feiras livres que inclusive possuem papel importante na disponibilização desse tipo de alimento para a população urbana. Em Minas Gerais as feiras livres assumem papel de destaque na comercialização da produção oriunda da agricultura fami- liar, dentre eles as hortaliças (Fernandes \& Campos, 2003).

A feira-livre é um canal que permite o relacionamento direto entre o produtor e o consumidor final (Machado \& Silva, 2005). Isso torna possível identificar mais facilmente as necessidades e desejos do consumidor e melhorar os aspectos tanto da produção quanto da comercialização, visto que, conforme 
afirma (Vilela \& Henz, 2000), o mercado de hortaliças é bastante dinâmico, sendo fortemente influenciado pela preferência dos consumidores, ao ponto de redirecionar a produção. Desta forma, o conhecimento do perfil dos consumidores é fundamental para que os produtores possam adequar sua oferta às necessidades específicas do público.

Poucas informações existem a respeito da importância das feiras no cotidiano das pessoas quanto ao consumo de hortaliças e quanto aos fatores que estreitam o relacionamento entre a feira e os consumidores na região do norte de Minas Gerais. Diante disso objetiva-se com esse trabalho analisar as características de consumidores de hortaliças em feiras livres, em cidades situadas na microrregião de Januária, norte de Minas Gerais.

\section{MATERIAL E MÉTODOS}

A população pesquisada consistiu de consumidores que compravam hortaliças em feiras livres, situadas em quatro municípios da microrregião de Januária, no norte de Minas Gerais: Chapada Gaúcha, Januária, Itacarambi e Manga. Os municípios possuem feiras livres já consolidadas que acontecem periodicamente na sexta-feira, sábado, domingo e segunda-feira, respectivamente. Essas feiras caracterizam-se por serem tradicionalmente abastecidas por produtores rurais da região.

Empregou-se a técnica de pesquisa mediante entrevistas diretas com questionários, que segundo Mattar (1999), é uma forma tradicional para coleta de dados primários (dados que nunca foram coletados, tabulados e analisados), realizada através da comunicação direta com o detentor dos dados, sendo o dado obtido pela declaração do próprio respondente, o que caracteriza o uso de entrevistas. Perez et al. (2008) e Andreuccetti et al. (2005) utilizaram questionários e entrevistas como meio de coletar informações junto aos consumidores por ser uma metodologia fácil, rápida e eficiente para obtenção de dados.

Consideraram-se público alvo os consumidores, ou seja, as pessoas que efetivamente compraram hortaliças na feira livres dos municípios. A entrevista se deu de forma individual na qual não foi privilegiado nenhum grupo de pessoas. Os consumidores de hortaliças foram abordados de forma aleatória após o término das compras. As entrevistas foram orientadas por questionários semi-estruturados, incluindo questões fechadas e questões abertas. Estes foram aplicados no período de 24 a 27 de junho de 2011, sendo um dia em cada município.

O número de questionários aplicados correspondeu ao total de entrevistas que se conseguiu realizar pela equipe de 5 pessoas, das $07 \mathrm{~h} 00 \mathrm{~min}$ às $12 \mathrm{~h} 00 \mathrm{~min}$. Assim, as feiras com maior volume de freqüentadores proporcionaram maior número de entrevistas. Aplicou-se 14 questionários em Chapada Gaúcha, 37 em Januária, 30 em Itacarambi e 26 no município de Manga.

$\mathrm{O}$ questionário constituiu-se de 11 perguntas para determinação do perfil dos consumidores: 1) idade; 2) sexo; 3) aposentado (a) ou não (b); 4) vem à feira toda semana; 5) qual a freqüência; 6) hortaliças que costuma comprar; 7) compra hortaliças somente na feira; 8) hortaliças que não encontraram na feira e desejaria adquirir; 9) compraria/ consumiria uma hortaliça diferente/ desconhecida; 10) porque compra na feira; 11) quanto gasta em média com hortaliças por compra.

Após as entrevistas realizou-se o levantamento dos dados obtidos e estes foram analisados considerando as variáveis abordadas no sentido de possibilitar a aproximação de indivíduos e variáveis numéricas em conjuntos de dados expressos em porcentagem, traçando o perfil do consumidor de hortaliças na região.

Foi realizada uma análise gráfica dos dados e utilizou-se a estatística de qui-quadrado para verificar a ocorrência de independência entre as variáveis obtidas por meio das respostas dos consumidores. Valores de probabilidade encontrados menores de 0,05 indicam que o teste foi significativo e as variáveis independentes. O Qui-quadrado só pode ser aplicado com rigor quando se verificam todas as condições seguintes: 1) $N>20$; 2) não apresentar frequências esperadas nulas; 3) no mínimo 80\% das frequências esperadas sejam superiores ou iguais a 5 (Maroco, 2007). Quando essas premissas não foram satisfeitas, utilizou-se como alternativa o teste não paramétrico Phi. Nos casos em que houve a impossibilidade da aplicação de alguns dos testes citados, ocorreu a análise descritiva dos resultados.

\section{RESULTADOS E DISCUSSÃO}

Os resultados referentes ao sexo dos consumidores evidenciaram que há maior participação dos consumidores do sexo feminino na feira livre de todos os municípios estudados. Nota-se também que a proporção de mulheres em Chapada Gaúcha (100\%) e Manga (83\%) é superior aos municípios de Itacarambi (67\%) e Januária (65\%). Em Chapada Gaúcha a atividade agropecuária é bastante desenvolvida, e acredita-se que a maior parte da população masculina esteja envolvida em alguma dessas atividades. Como em Chapada Gaúcha e Manga, as feiras acontecem em dias de semana, na sexta-feira e segunda-feira respectivamente, são mulheres que se responsabilizam pela compra de hortaliças. Não foram abordadas questões sobre o trabalho fora de casa. Esses resultados são semelhantes aos encontrados por Silva \& Costa (2011) na feira de Pombal-PB, onde ocorre predominância de mulheres nas compras. Segundo os autores elas são as maiores responsáveis pela tomada de decisão de compra, além de se demonstrarem atenciosas aos detalhes na escolha do produto.

Em Campinas-SP, o comercio em supermercados, especificamente para compra de tomate de mesa houve maior proporção de mulheres (73\%), conforme revelam Andreuccetti et al. (2005), pois as mulheres ainda são as principais responsáveis pela compra de alimentos de sua família.

$\mathrm{Na}$ Feira dos Produtores de Passo Fundo-RS 51\% dos consumidores são homens (Rocha et al., 2010). Os autores relacionam com o fato de serem indivíduos provavelmente aposentados ou aproximando-se da aposentadoria, que utilizam a feira como forma de distração. Fato semelhante pode estar 
Tabela 1. Frequência relativa de consumidores (\%), em função da ida à feira (IF); compra somente na feira (CF); compra de hortaliças desconhecidas (CHD); motivo para compra na feira livre (MC) e dos municípios pesquisados \{relative frequency of consumers (\%), depending on visits to the street market (IF); buy only at the street markets (CF); purchase of unknown vegetables (CHD); reason for sale at the street markets (MC) and municipalities surveyed . Montes Claros, UFMG, 2012.

\begin{tabular}{lcccc}
\hline Municípios & $\begin{array}{c}\text { Semanalmente } \\
\text { (IF) }\end{array}$ & $\begin{array}{c}\text { Sim } \\
\text { (CF) }\end{array}$ & $\begin{array}{c}\text { Sim } \\
\text { (CHD) }\end{array}$ & $\begin{array}{c}\text { Qualidade/tradição } \\
\text { (MC) }\end{array}$ \\
\hline Chapada G. & 57 & 29 & 86 & 78 \\
Itacarambi & 90 & 40 & 67 & 82 \\
Januária & 86 & 68 & 68 & 76 \\
Manga & 76 & 66 & 54 & 59 \\
\hline média & 83 & 56 & 65 & 72 \\
teste & $P h i^{\text {ns }}$ & $P h i^{*}$ & $P h i^{\text {ns }}$ & Qui-quadrado $^{\text {ns }}$ \\
\hline
\end{tabular}

${ }^{\text {ns }}$ não significativo a 5\%; significativo a $5 \%\left({ }^{n s}\right.$ not significant at 5\%; $*$ significant at $5 \%$ ).

Tabela 2. Frequência relativa (\%) de consumidores, em função do valor gasto com a compra de hortaliças e dos municípios pesquisados \{relative frequency of consumers (\%), depending on the amount spent on the purchase of vegetables and municipalities surveyed $\}$. Montes Claros, UFMG, 2012.

\begin{tabular}{lccc}
\hline \multirow{2}{*}{ Municípios } & \multicolumn{3}{c}{ Gasto por feira (R\$) } \\
\cline { 2 - 4 } & $\mathbf{1 0 , 0 0 - 2 0 , 0 0}$ & $\mathbf{2 1 , 0 0 - 3 0 , 0 0}$ & $>\mathbf{3 0 , 0 0}$ \\
\hline Chapada G. & 100 & 0 & 0 \\
Itacarambi & 24 & 28 & 48 \\
Januária & 32 & 27 & 41 \\
Manga & 39 & 26 & 35 \\
\hline
\end{tabular}

Não significativo a $5 \%$ pelo teste $P h i(p$-valor $=0,400 ; \mathrm{N}=98)$ \{not significant at $5 \%, P h i$ test ( $\mathrm{p}$-value $=0,400 ; \mathrm{N}=98)\}$.

acontecendo em Itacarambi e Januária que apresentam feiras no fim de semana, domingo e sábado respectivamente.

$\mathrm{Na}$ amostra estudada, houve a predominância de consumidores na faixa etária de até 54 anos em todos os municípios, ou seja, pode-se considerar que os consumidores são relativamente jovens. Do total de homens entrevistados nas feiras estudadas, $67 \%$ apresentaram idade inferior a 54 anos; já para as mulheres esse índice subiu para $75 \%$. Estes valores não diferiram estatisticamente pelo teste de Qui-quadrado ( $p$-valor = $0,251 ; \mathrm{N}=98)$ a $5 \%$ de probabilidade, indicando que não há relação de dependência entre os parâmetros idade e sexo dos consumidores. Essa situação é diferente da encontrada por Rocha et al. (2010) na feira de Passo Fundo-RS que apresentou homens com idade mais avançada sendo esta superior a 55 anos, é de 54 anos. Essa característica pode influenciar diretamente na pauta alimentar e nos produtos adquiridos na feira, e consequentemente ditam as espécies de hortaliças produzidas e comercializadas na feira.

Na região do vale do Jequitinhonha, Ribeiro (2007) atribui grande parte do dinamismo da feria livre aos aposentados e aos pensionistas. Mesmo nos municípios estudados, a pouca presença de consumidores aposentados na feira, não impede que seus recursos financeiros sejam usados na compra de hortaliças. Um indicativo é o relato de melhora nas vendas na primeira quinzena dos meses, pelos feirantes nos municípios de Chapada Gaúcha, Itacarambi, Januária e Manga. Porém, mais estudos devem ser realizados para investigar melhor essa questão.

Com relação à porcentagem de aposentados em função do sexo, observou-se que, do total de consumidores do sexo masculino, $30 \%$ eram aposentados e para mulheres esse valor decresce para $25 \%$. Segundo o teste Qui-quadrado (p-valor $=4,754 ; \mathrm{N}=98$ ), não ocorre relação entre a condição de aposentadoria e sexo, sendo a porcentagem de homens aposentados um pouco maior, correspondendo aos resultados referentes à idade dos consumidores de hortaliças nos municípios estudados.

A maior parte dos consumidores costuma ir à feira toda semana. Nota-se que, em Chapada Gaúcha, essa porcentagem é um pouco menor (Tabela 1). A feira de Chapada Gaúcha é a menor e a mais nova das quatro feiras estudadas e não apresenta grande variedade de produtos para atrair os consumidores, além disso, a população de Chapada Gaúcha culturalmente utiliza os mercados e sacolões para compras de hortaliças. Em Campinas-SP, os consumidores têm o hábito de comprar hortaliças semanalmente tanto em supermercados quanto nas feiras livres (Fonseca et al., 1999). Como as hortaliças são produtos perecíveis, é natural que as compras sejam realizadas mais vezes durante $o$ mês, justificando a maior porcentagem de consumidores que freqüentam a feira semanalmente.

$\mathrm{Na}$ mesma tabela, apresentam-se os resultados das porcentagens de 


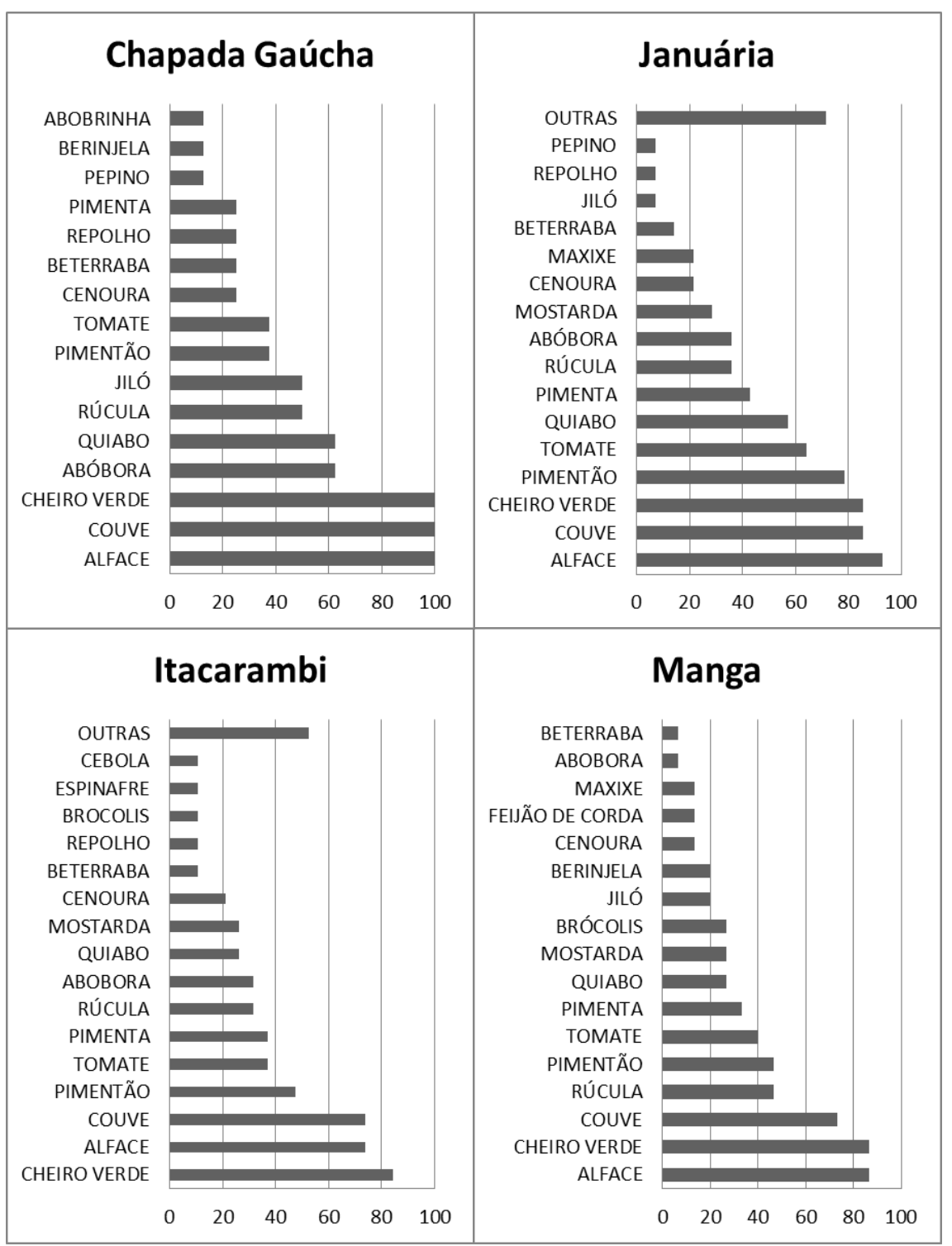

Figura 1. Principais hortaliças adquiridas por consumidores nas feiras livres dos municípios estudados (major vegetables purchased by consumers in street markets of municipalities surveyed). Montes Claros, UFMG, 2012.

consumidores que utilizam somente a feira livre para comprar as hortaliças. Houve diferença estatística pelo teste $P h i$, indicando a dependência entre a característica de compra de hortaliças exclusivamente na feira e nos municípios. Notam-se, em Chapada Gaúcha e Itacarambi, que os consumidores utilizam outros estabelecimentos, como varejões e supermercados. Já em Januária e em Manga a maior parte dos consumidores utiliza a feira livre. Januária e Manga já são feiras tradicionais e consolidadas, que atendem melhor às expectativas dos clientes. Os supermercados e sacolões/varejões são grandes concorrentes das feiras livres na venda de produtos hortícolas e frutas. Como os sacolões e supermercados funcionam diariamente, os consumidores tendem a aproveitar a ida a esses estabelecimentos para comprar também hortaliças. A população de Chapada Gaúcha e Itacarambi possui hábitos de compra de hortaliças mais voltados para os mercados e sacolões. Cabe investigar nesses municípios o real motivo de tal preferência. Uma tendência forte seria a falta de estrutura das feiras, como falta de higiene, lixeiras, banheiros, bebedouros e no caso específico de Chapada Gaúcha a feira localiza-se mais distante do centro comercial do município.

Em São Francisco-MG (Silvestre et al., 2011), 54,5\% dos consumidores dão preferência à feira livre porque alguns produtos somente são encontrados na feira, como por exemplo produtos do extrativismo, tempero caseiro, frango caipira, maxixe, quiabo entre outros. Para os demais $(45,5 \%)$ há produtos exclusivos das feiras. Desta forma, se os consumidores não encontrarem o produto na feira, a maior parte deles $(60 \%)$ não deixa de comprá-los em outros estabelecimentos. Esse resultado mostra que o comércio apresenta-se como um potencial substituto para a maioria dos consumidores, mas enfatizando que só o fazem na não disponibilidade do produto na feira livre.

Na Tabela 1, estão as respostas dos consumidores ao serem indagados sobre o consumo de hortaliças diferentes ou desconhecidas. Em todos os municípios, os consumidores comprariam espécies desconhecidas para diversificar a alimentação da família. Esse resultado evidencia a aceitação por parte dos consumidores à diversificação de produtos, sendo um nicho de mercado que os feirantes podem explorar para assegurar a manutenção e até mesmo a elevação da renda durante o ano.

As hortaliças não-convencionais podem suprir essa demanda por algo novo. Elas mostram-se com grande potencial, pois são hortaliças mais rústicas produzindo bem sem muitos tratos culturais, além de gerarem produtos de qualidade, com boa aparência e paladar, sem contar a questão nutricional que, de maneira geral, mostra-se superior às hortaliças convencionais.

Nos resultados obtidos com relação aos motivos que levam os consumidores a comprar hortaliças nas feiras livres, que constituiu-se de questão aberta, as respostas convergiram para duas situações principais: a qualidade dos produtos ofertados e a tradição de compra de hortaliças na feira, principalmente nos Municípios de Chapada Gaúcha, Itacarambi, Januária e em menor proporção no município de Manga (Tabela 1). Nas respostas sobre a qualidade das hortaliças, o consumidor se refere à produção no manejo orgânico sem agrotóxicos e adubos químicos. A proximidade entre 
consumidor e feirantes possibilita a troca de informações sobre a origem dos produtos, gerando laços de confiança. A afirmação pode ser comprovada pelos relatos dos consumidores durante as repostas da referida questão, onde a maior parte diz que as hortaliças são produzidas de forma natural sem utilização de agrotóxicos. O baixo preço foi citado em menor proporção, como motivação para compra. No município de Manga há maior presença de feirantes atravessadores, que trazem hortaliças oriundas da CEASA de Montes Claros. Estes de maneira geral apresentam menores preços atraindo os consumidores, e ao mesmo tempo competem com os feirantes que produzem ou revendem produtos de agricultores familiares da região. Em Campinas-SP, o preço não é item importante na opção de compra em feiras livres, diferente do consumidor de supermercados e de sacolões (Fonseca et al., 1999).

Perguntou-se aos consumidores se havia alguma hortaliça que não encontravam na feira. A procura por hortaliças nas feiras livres parece ser direcionada, visto que a maior parte das respostas dos entrevistados a esta pergunta foi negativa em Chapada Gaúcha (29\%), Itacarambi (83\%), Januária (62\%) e Manga (71\%). Além das feiras livres, os entrevistados utilizam outros pontos comerciais para adquirirem hortaliças. Em Chapada Gaúcha (71\%), Itacarambi (73\%), Januária (60\%) e Manga (63\%) os entrevistados relataram freqüentar sacolões e supermercados. Há indícios de que os entrevistados elegem a compra de determinadas hortaliças conforme o segmento de comércio. Apesar disso, estes gostariam de encontrar regularmente algumas hortaliças nas feiras, como, batata, jiló, quiabo, repolho e tomate em Chapada Gaúcha; alcachofra, pepino e rúcula, em Itacarambi; agrião, alho, alho-porró, cebola espinafre, inhame, jiló, mostarda, nabo, ora-pro-nóbis, pepino, quiabo e taioba em Januária; almeirão, berinjela, jiló, pepino, pimenta, rabanete e rúcula em Manga. Já brócolis e couve-flor foram citados em todas as cidades, indicando o potencial de comercialização dessas hortaliças. Há cultivares adaptadas ao clima quente para essas duas hortaliças, como Piracicaba Precoce (verão) e IAC Santa Elisa de Couve-Flor e Ramoso Santana, de Brócolis.

Estudos específicos podem indicar espécies a serem usadas pelos comerciantes para diversificação dos produtos oferecidos nas feiras e também para evitar a concorrência entre os feirantes. Nota-se que a demanda de hortaliças pelos consumidores de Chapada Gaúcha, corresponde justamente às hortaliças normalmente ofertadas em supermercados e em sacolões. Januária apresentou a maior variedade de espécies citadas pelos consumidores; dentre elas, aparecem algumas espécies não-convencionais como taioba, ora-pro-nóbis e inhame, confirmando que os consumidores de hortaliças de Januária (38\%) são mais tradicionais e procuram na feira, suprir essa necessidade alimentar, de produtos que provavelmente foram culturalmente passados de pai para filho.

Brandão (1981) fez relatos sobre a alimentação no processo de transição de uma comunidade rural para a cidade. Ficou evidente a influência da cultura na alimentação dessa parte da população urbana, que tende sempre que possível, buscar alimentos comuns na pauta alimentar do ambiente rural. Acredita-se que fatores como prazer, importância atribuída a alimentos sem "produtos químicos" e principalmente a necessidade econômica movam as pessoas a plantar retirando boa parte de sua alimentação do próprio quintal, buscando também no mercado informal, como em feiras livres, que, comumente, oferecem esse tipo de produto. Em Januária, os resultados indicam que alguns entrevistados buscam hortaliças mais tradicionais, sugerindo maior influência do meio rural na pauta alimentar dessa parte da população.

No município de Chapada Gaúcha, o gasto ficou entre R\$10,00 e R\$20,00, por ida à feira (Tabela 2). É uma feira pequena, com poucos anos de funcionamento e com pouco movimento, o que inviabiliza e desestimula os agricultores em oferecer maior variedade de produtos, espécies e cultivares, e em maior quantidade. Desta forma o volume de compras è reduzido em relação às outras feiras estudadas. Alguns feirantes chegaram a reclamar da localidade da feira que é um pouco afastada do centro comercial do município. Itacarambi, Januária e Manga foram os municípios que apresentaram os maiores gastos pelos consumidores com hortaliças.

Em Bom Jesus-PI o gasto médio com hortaliças em cada compra na feira foi de $\mathrm{R} \$ 10,00$ a $\mathrm{R} \$ 20,00$ para a maioria dos consumidores (Moreira et al., 2012). As hortaliças, principalmente folhosas, apresentam baixo preço e, como são muito perecíveis, são compradas em pouca quantidade e com maior freqüência. Em Itacarambi, em Januária e em Manga os valores são superiores a R\$ 30,00. De acordo com Azevedo \& Faulin (2003), os consumidores de hortaliças fazem suas compras uma vez por semana, devido ao alto grau de perecibilidade e por esse motivo, compram em menor quantidade refletindo assim no valor gasto.

Na Figura 1, estão apresentadas as principais hortaliças compradas pelos consumidores em feiras livres. Através dos resultados observa-se que, em todas as cidades prevalecem alface, couve e cheiro verde, corroborando as hortaliças mais produzidas e comercializadas pelos feirantes. Esse resultado indica que a produção de hortaliças está intimamente ligada ao consumo. Desta forma, como os consumidores estão abertos a incorporar novidades à sua pauta alimentar, a diversificação da produção pelos feirantes seria bem aceita pelos consumidores. Segundo Cruz et al. (2008), tomate, alface, coentro, cebola, pimentão e cebolinha foram as hortaliças mais adquiridas pelos consumidores da feira livre de Bom Jesus-PI. Conforme Castelo Branco et al (2006), o tomate e a alface são as hortaliças respectivamente, mais consumidas no Brasil.

O conhecimento das características, costumes e expectativas dos consumidores que frequentam feiras livres é importante para auxiliar programas de incentivo a produtores de hortaliças que comercializam em feiras.

As mulheres foram responsáveis pela compra de hortaliças nas feiras estudadas, principalmente nas que ocorrem na sexta-feira e segunda-feira, Chapada Gaúcha e Manga respectivamente. A oferta de produtos sem uso de agrotóxicos e fertilizantes químicos 
gera confiança e fidelização dos consumidores. Os entrevistados parecem direcionar as espécies de hortaliças que dão preferência para compra na feira livre. A maioria dos consumidores entrevistados em Itacarambi e Januária, afirmou gastar mais de $\mathrm{R} \$ 30,00$ por ida à feira e em Manga e Chapada Gaúcha gastam entre $\mathrm{R} \$ 10,00$ e R\$20,00.

O trabalho indicou potencialidade de expansão da comercialização de hortaliças em feiras livres na região, pois espécies como brócolis e couve-flor foram lembradas por parte dos entrevistados e não são encontradas nas feiras da região com freqüência. Outras espécies e ou variedades de hortaliças também podem ser utilizadas para abrir novas oportunidades de produção e comercialização.

\section{AGRADECIMENTOS}

Ao $\mathrm{CNPq}$ pelo apoio financeiro ao projeto: Pesquisa e extensão com sistemas agroextrativista de agricultores familiares tradicionais do Alto-Médio São Francisco, norte do Estado de Minas Gerais. Edital MCT/CNPq Nº 029/2009.

\section{REFERÊNCIAS}

ANDREUCCETTI C; FERREIRA MD;
TAVARES M. 2005. Perfil dos compradores de tomate de mesa em supermercados da região de Campinas. Horticultura Brasileira 23: $148-153$.

AZEVEDO PF; FAULIN EJ. 2003. Distribuição de hortaliças na agricultura familiar: uma análise das transições. Informações Econômicas 33: 24-37.

BRANDÃO CR. 1981. Plantar, colher e comer. Rio de Janeiro: Graal. 181p.

CASTELO BRANCO M; NOGUEIRA JM; SANTOS RC. 2006. Perfil dos consumidores de hortaliças da cidade de Santo Antônio do Descoberto-GO. Horticultura Brasileira 24: 368-372.

CERDEÑO VJM. 2006. Hábitos de compra y consumo de frutas y hortalizas - Resultados del Observatório del Consumo y La Distribución Alimentaria. Distribución y Consumo 88: 5-28.

CRUZ PP; MOREIRA GR; FERREIRA FS; MORAES FB; SOUZA FJL; MOURA FJG; COELHO RF; LIMA MPD; CARVALHO RM; ALÉNDIAAA. 2008. Perfil dos consumidores de hortaliças da feira livre de Bom Jesus, Piauí. Horticultura Brasileira 26: 630-635.

FERNANDES FILHO JF; CAMPOS FR. 2003. A indústria rural no Brasil. Revista de Economia e Sociologia Rural 41: 859-880.

FONSECA MCP; AZEVEDO MA; SALAY EPS. 1999. Atitudes dos consumidores com relação à compra de hortifrutícolas em hipermercados e feiras livres na cidade de Campinas-SP. Cadernos de Ciência \& Tecnologia 16: 87-113.

MACHADO MD; SILVA AL. 2005. Canais de distribuição para produtos da agricultura familiar. In: SOUZA FILHO HM; BATALHA MO. (org). Gestão integrada da agricultura familiar. São Carlos: Edufscar. p.95-129.

MAROCO J. 2007. Análise estatística com a utilização do SPSS. Lisboa: Silabo. 822p.

MATTAR FN. 1999. Pesquisa de marketing: metodologia e planejamento. São Paulo:
Atlas. 339p.

MOREIRA GR; CRUZ PP; FERREIRA FS; Rodrigues MG. 2012. Perfil dos compradores de hortaliças da feira livre de Bom Jesus-PI. Enciclopédia Biosfera 8: 2518-2527.

PEREZ R; RAMOS AM; BINOTI ML; SOUSA PHM; MACHADO GM; CRUZ IB. 2008. Perfil dos consumidores de hortaliças minimamente processadas de Belo Horizonte. Horticultura Brasileira 26: 441-446.

RIBEIRO EM. 2007. (org). Feiras do Jequitinhonha: mercados, cultura e trabalho de familias rurais do semiárido de Minas Gerais. Fortaleza: Etene/BNB. 246p.

ROCHA HC; COSTA C; CASTOLDI FL; CECCHETTI D; CALVETE EO; LODI BS. 2010. Perfil socioeconômico dos feirantes e consumidores da Feira do Produtor de Passo Fundo-RS. Ciência Rural 40: 2593-2597.

SILVA DSOS; COSTA CC. 2011. Identificação dos consumidores de hortaliças da feira livre de Pombal-PB: aspectos socioeconômicos e culturais. Revista Verde 6: 56-60.

SILVESTRE LHA; RIBEIRO AEM; FREITAS CS. 2011. Subsídios para a construção de um programa público de apoio à feira livre no vale do São Francisco-MG. Organizações Rurais \& Agroindustriais 13: 186-200.

VILELA NJ; HENZ GP. 2000. Situação atual da participação das hortaliças no agronegócio brasileiro e perspectivas futuras. Cadernos de Ciência \& Tecnologia. 17: 71-89. 